\title{
3D RECORDING, MODELLING AND VISUALISATION OF THE FORTIFICATION KRISTIANSTEN IN TRONDHEIM (NORWAY) BY PHOTOGRAMMETRIC METHODS AND TERRESTRIAL LASER SCANNING IN THE FRAMEWORK OF ERASMUS PROGRAMMES
}

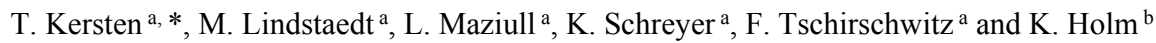 \\ a HafenCity University Hamburg, Photogrammetry \& Laserscanning Lab, Überseeallee 16, 20457 Hamburg -(thomas.kersten, \\ maren.lindstaedt, kristin.schreyer, felix.tschirschwitz)@hcu-hamburg.de, Lena-Maziull@web.de \\ ${ }^{\mathrm{b}}$ NTNU - Norwegian University of Science and Technology, Division of Roads, Transport, and Geomatics, Høgskoleringen 7 A, \\ NO-7491 Trondheim, Norway - knut.r.holm@ntnu.no
}

Commission V - WG V/4

KEY WORDS: 3D, CAD, meshing, model, reconstruction, virtual

\begin{abstract}
:
In this contribution the 3D recording, 3D modelling and 3D visualisation of the fortification Kristiansten in Trondheim (Norway) by digital photogrammetry and terrestrial laser scanning are presented. The fortification Kristiansten was built after the large city fire in the year 1681 above the city and has been a museum since 1997. The recording of the fortress took place in each case at the end of August/at the beginning of September 2010 and 2011 during two two-week summer schools with the topic "Digital Photogrammetry \& Terrestrial Laser Scanning for Cultural Heritage Documentation" at NTNU Trondheim with international students in the context of ERASMUS teaching programs. For data acquisition, a terrestrial laser scanner and digital SLR cameras were used. The establishment of a geodetic 3D network, which was later transformed into the Norwegian UTM coordinate system using control points, ensured a consistent registration of the scans and an orientation of the photogrammetric images. The fortress buildings were constructed in detail from photogrammetric photographs and point clouds using AutoCAD, while the fortress area and walls were modelled by triangle meshing in Geomagic. The visualisation of the fortress was carried out 2013 with the software Cinema 4D in the context of a lecture in the Master study programme Geomatics. The 3D model was textured and afterwards presented in a video. This 3D model was finally transferred into the game engine Unity for an interactive $3 \mathrm{D}$ visualisation on $3 \mathrm{D}$ monitors.
\end{abstract}

\section{INTRODUCTION}

The Erasmus programme is a student exchange programme of the European Union. Although its name reminds of Erasmus of Rotterdam, a European formed philosopher of the Renaissance, ERASMUS is a backronym meaning "EuRopean Community Action Scheme for the Mobility of University Students" at the same time (DAAD 2012). Beside the 28 European Union member states also further states such as Norway participate in the world-wide largest funding programme of stays abroad at universities. Central components are the formal recognition of study achievements abroad based on the European Credit Transfer System (ECTS) and the financial support of exchange students, who regularly study at a participating university. Apart from study stays and foreign internships in the context of the study also training stays as well as advanced training of general university staff can be financially supported. Basis for the exchange of students and lecturer is an appropriate bilateral agreement between in-going and out-going universities.

The Photogrammetry \& Laser Scanning Lab of HafenCity University Hamburg accomplished two-week summer schools in co-operation with NTNU (Norwegian University of Science and Technology, Department of Civil and Transport Engineering Division of Roads, Transport, and Geomatics) in Trondheim three times in the years 2009 to 2011 with the topic "Digital Photogrammetry \& Terrestrial Laser Scanning for Cultural Heritage Documentation" in the context of ERASMUS Teaching programmes. In the practical part of the summer school historical buildings were recorded in each case by photogrammetry and terrestrial laser scanning, and their data were processed afterwards in the course. Bases of these summer schools are the courses Architectural Photogrammetry of the Bachelor study programme and the module Terrestrial Laser Scanning of the Master study programme Geomatics of the HCU Hamburg (see also Kersten 2005).

In the context of these two courses the Photogrammetry \& Laser Scanning Lab of HCU Hamburg has already documented architecturally significant buildings in Northern Germany for 15 years by photogrammetry and terrestrial laser scanning (Kersten \& Acevedo Pardo 2003, Kersten et al. 2003, Kersten et al. 2004, Kersten et al. 2006, Kersten \& Lindstaedt 2012). Documentation of the following complex architectural objects are further examples of project works of HCU Hamburg in 3D modelling: The northern sluice of the ancient dam in Marib/Yemen (Kersten 2007), the historical peninsula in Istanbul (Kersten et al. 2009), the Almaqah temples in Sirwah/Yemen (Lindstaedt et al. 2008) and in Yeha/Ethiopia (Lindstaedt et al. 2010), as well as the Al Zubarah fortress in Qatar (Kersten \& Mechelke 2013).

In this contribution the $3 \mathrm{D}$ object recording, 3D modelling and visualisation of the fortification Kristiansten in Trondheim (Norway) using terrestrial laser scanning and digital photogrammetry, is introduced. After a brief introduction of the fortress Kristiansten, the summer school is described. Afterwards the practical work is described with focus on the modelling and visualisation of the captured object.

\footnotetext{
* Corresponding author
} 


\section{THE FORTIFICATION KRISTIANSTEN IN TRONDHEIM}

Kristiansten Fortress (shown in Figure 1) is a fortification on the eastern side of the city of Trondheim. The fortress is built on a strategically important hill above the Old City Bridge, which was the main entrance to the city from north and east. From this hill it was possible to shoot into the city, and Swedish troops had controlled the city from this hill in 1564 and 1658. Plans for a fortification in this area were made in 1676 , but nothing was done until after the big city fire in 1681 .

When the two engineering officers Johan Caspar de Cicignon and Anthony Coucheron were sent to Trondheim to create a new city plan after the fire, they also built the fortress. The construction started 1682, and 1684 it was already finished (KAVLI 1987). The original plan was a symmetrical, star-shaped fortification around a central tower, the Donjon. However, the walls were adjusted to the terrain, and the shape became an irregular star with nine corners.

During the years several changes have been made. After being rebuilt in 1740, it has more or less kept its present shape. In the northern part, there are casemates, i.e. arched rooms connected to the inside of the outer walls. The casemates were used for accommodation, food storage, kitchen, prison, etc. They are well kept, and still in use for various purposes. There are three individual buildings on the fortress; the Commander's Residence, which is a modest one floor house, the guard house, standing close to the Commander's Residence, and the Donjon, the main tower.

The Donjon is a whitewashed stone building, appearing as a significant landmark of Trondheim. It covers $17 \mathrm{~m}$ by $15 \mathrm{~m}$, the height is $20 \mathrm{~m}$ and the wall thickness is four meters. The building has a cellar for storing gunpowder. The ground floor was originally used as residence for the commander. The next two floors were for cannons, which could be fired in all directions. The wooden floors are very robust, made to endure the weight and recoil from the guns. There is also a top floor, behind the roof, used as observation post.

The fortress has been in combat only once, during the great Nordic war. The Swedish king Karl XII sent General Carl Gustaf Armfeldt with ten thousand men to Trondheim in 1718. He was not able to capture the fortress, and thus he failed to capture Trondheim. After the death of Karl XII, Armfeldt and his men had a disastrous retreat over the mountains back to Sweden during the winter 1718/1719, where most of his men died.

In 1814 Norway was forced into a union with Sweden. Kristiansten was decommissioned by the Swedish/Norwegian king Karl III Johan 1816, and it was left to "deterioration by the time". However, the maintenance was continued because of its function as fire watch and fire alarm.

During the German occupation of Norway in World War II, a number of Norwegian patriots were executed at Kristiansten. After the war, the fortress was the execution place for convicted traitors and war criminals in Norway. A historical summary about the fortification Kristiansten is found e.g. in Bratberg (2008).

The fortress has been renovated during the last years. The Donjon is a museum. The Commander's Residence is a restaurant. A memorial chapel is established in one of the casemates. And the whole fortress is a popular area for people to visit for walking and enjoying the view (see Figure 1). Salutations by cannons are done from the fortress on the National Day (May 17), at royal visits, and at other significant occasions. The New Year fireworks of the municipality are sent up from the fortress.

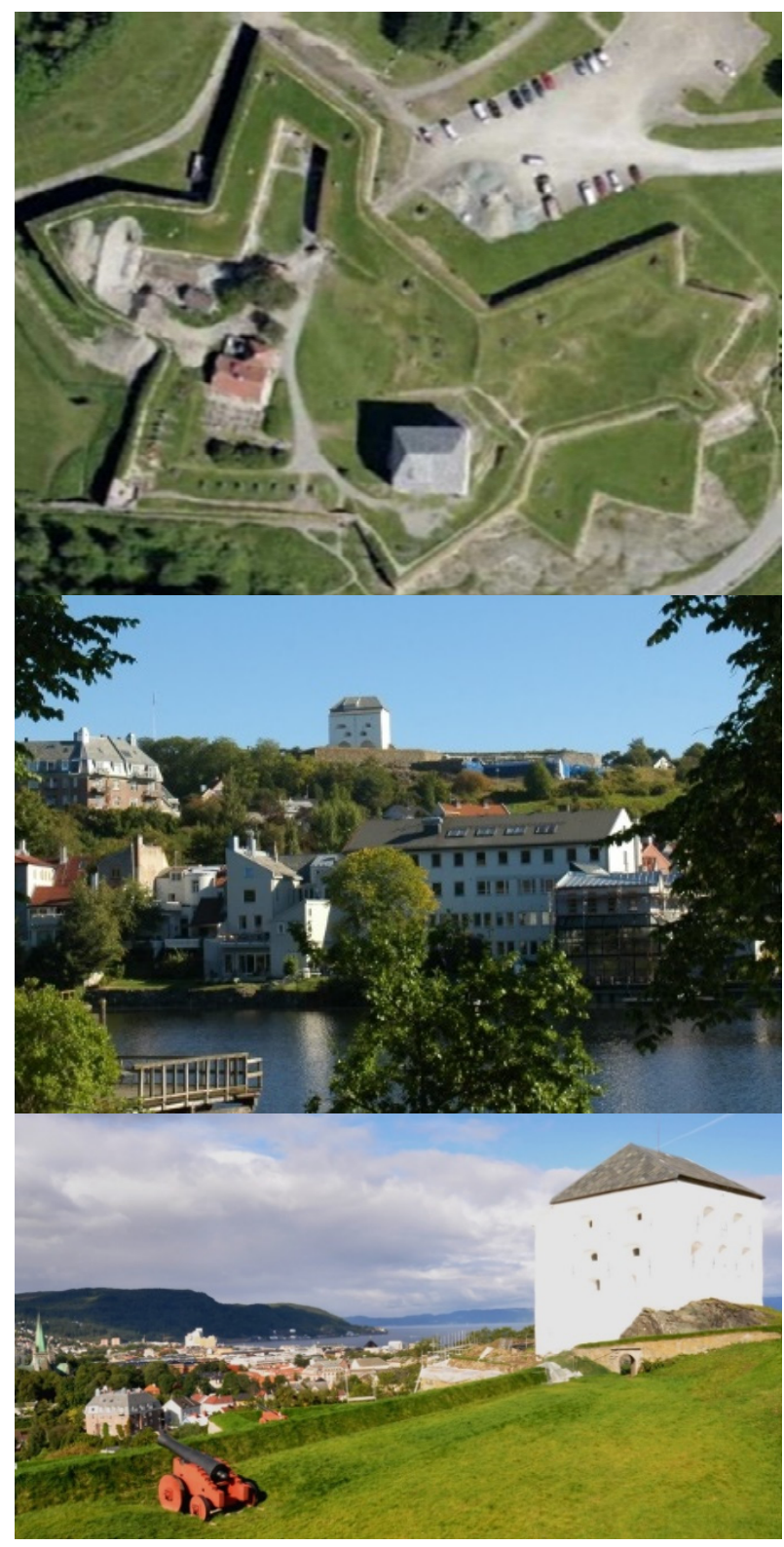

Figure 1: Fortification Kristiansten in Trondheim - nadir aerial photo (top, Google Earth), view from the city to the defence tower Donjon (centre) and view to the city (bottom)

\section{SUMMER SCHOOLS IN ERASMUS TEACHING PROGRAMMES}

In the years 2009, 2010 and 2011 three two-week summer schools with the topic "Digital Photogrammetry \& Terrestrial Laser Scanning for Cultural Heritage Documentation" in the context of the ERASMUS teaching programmes were performed at NTNU Trondheim. The content of each summer school was partitioned into a theoretical and practical part. In doing so, the lecture Architectural Photogrammetry (of the Bachelor study programme Geomatics) and the module Terrestrial Laser Scanning (of the Master study programme Geomatics) of HCU Hamburg formed the substantial content of the summer schools. In the first week, lectures on digital photogrammetry and terrestrial laser scanning were given in the theoretical part of each summer school. Focus areas in digital photogrammetry were 


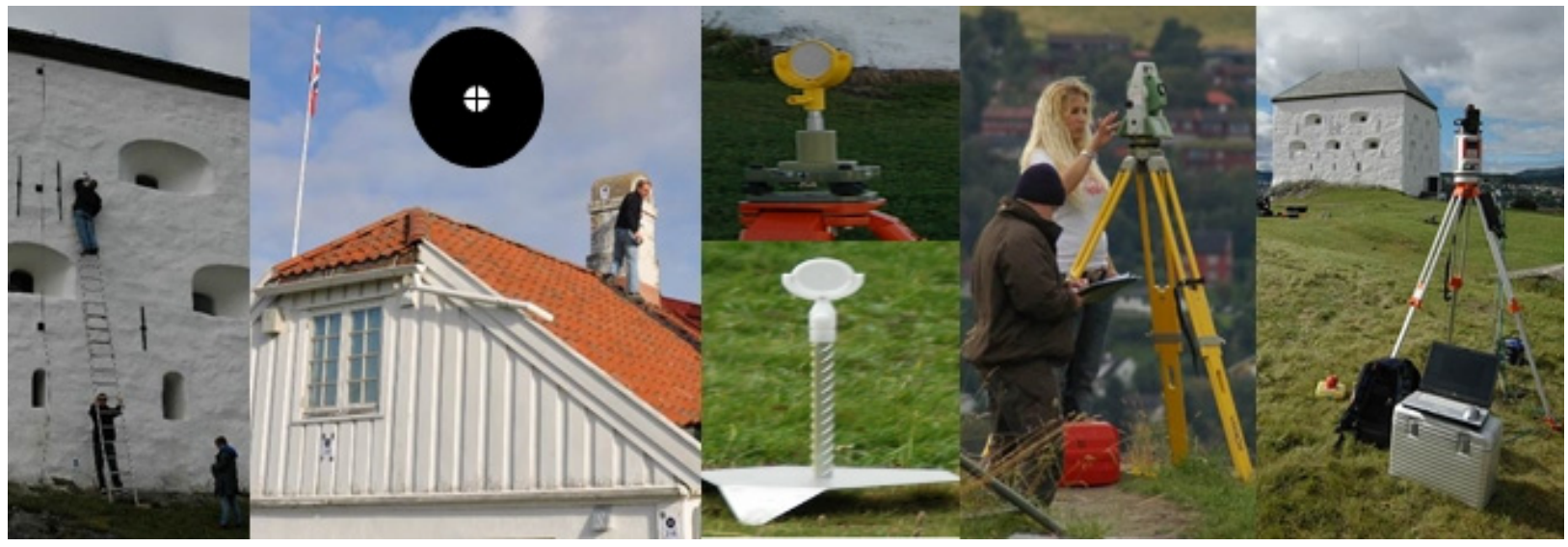

Figure 2: Control point signalisation at both fortress buildings, reflective targets for laser scanning, geodetic control point measurement and Riegl VZ-400 in use (f.l.t.r.)

digital camera systems, camera station configuration, project planning, control point determination, geodetic 3D network adjustment, image orientation and camera calibration by bundle block adjustment, $3 \mathrm{D}$ point determination in photos, $\mathrm{CAD}$ object reconstruction, modelling and visualisation. Terrestrial laser scanning was covered by the following topics: Measuring methods, systems, criteria for laser scanners, registration and geo-referencing, segmentation, filtering, geometrical accuracy tests, CAD object reconstruction from point clouds, modelling, 3D triangulation and meshing, and analysis of the results. For the practical part the participants worked mostly on a project in the second week. A total workload of 60 hours was defined for the summer schools in each case, which corresponds to two ECTS. The first summer school took place from 7 to 18 September 2009. As a practical project a section of the Nidaros cathedral inside and outside was photographed and scanned, since the NDR (Nidaros Domkirkes Restaureringsarbeider - The Restoration Workshop of the Nidaros Cathedral) was not only interested in data recording and evaluation procedures, but above all also in the data and results. Only in the second and third summer schools the participants were concerned with the fortification Kristiansten. In the second course, which took place from 30 August to 10 September 2010, primarily the fortress tower Donjon and parts of the internal area were recorded for object modelling, while in the third summer school from 29 August to 9 September 2011 the commandant's office, the internal area of the fort as well as the outside walls were recorded and processed. The number of participants of each summer school was between eight and ten students, which came from Norway, Germany, Poland and Finland.

\section{DATA RECORDING AND 3D MODELLING OF KRISTIANSTEN FORTIFICATION}

The data acquisition of the fortification was conducted on the third and fourth day of each summer school (01./02.09.2010 and 31.08./01.09.2011). In 1.5 days the following work was carried out (including preparation): measurement of a geodetic 3D network, signalisation and measurement of control points for photogrammetry and laser scanning, photogrammetric image recording and terrestrial laser scanning. The measurements of the geodetic 3D network were carried out with a total station Leica TCRP 1201 (see Figure 2), in which eight network stations were forced centring on stable tripods and were mutually measured, in order to ensure solid network geometry. The signalised control points (Figure 2) fixed at the two fortress buildings (Donjon and commandant's office) were measured from the network stations

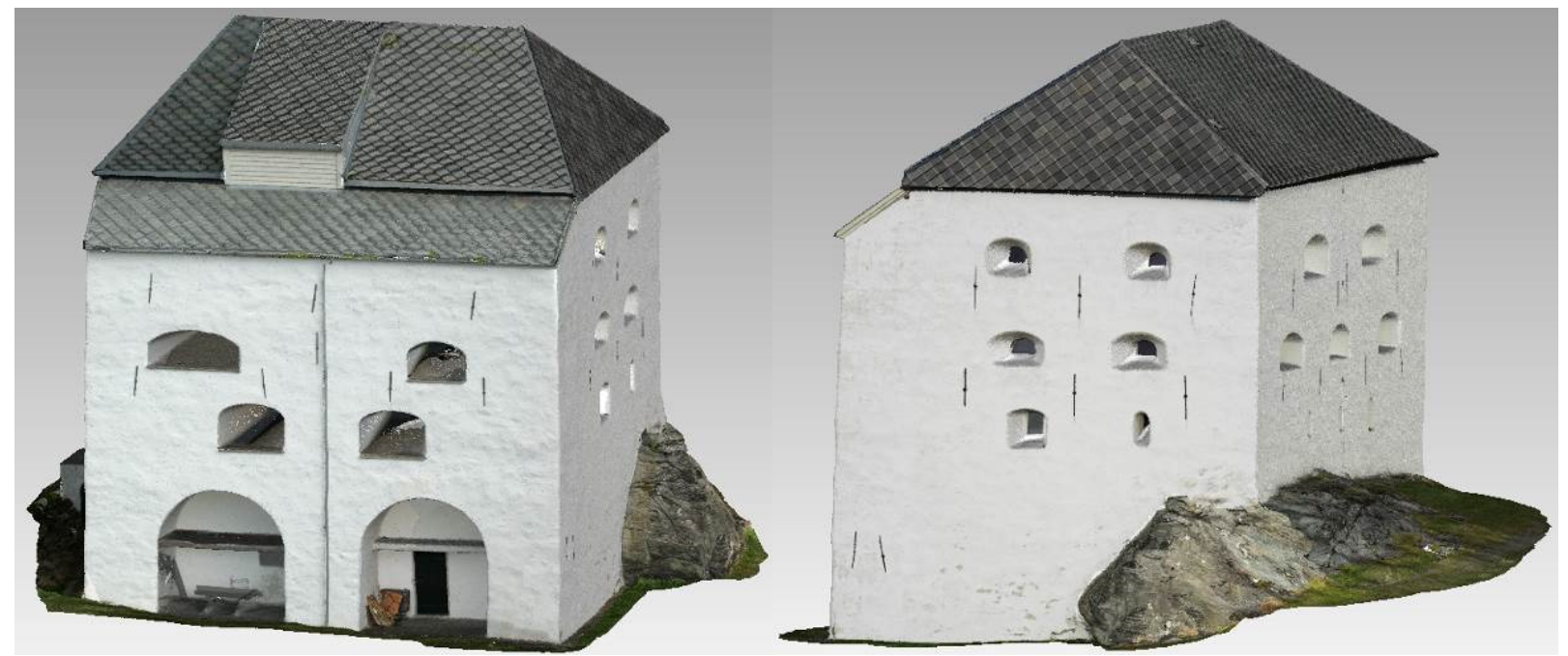

Figure 3: Perspective view of the defence tower (Donjon) modelled from point clouds - manual texture mapping on meshes in Geomagic 
and from free-stationing. The 3D network and the control points were adjusted using the software PANDA of GeoTec (Laatzen). The network stations were determined with a precision of less than $1 \mathrm{~mm}$ in both years, while the 28 signalised control points at the defence tower Donjon in 2010 and at the commandant's office in 2011 were adjusted with a precision of $2.5 \mathrm{~mm}$ in XY and $4 \mathrm{~mm}$ in $\mathrm{Z}$. The control point and network station coordinates computed in PANDA were transformed into the UTM coordinate system using three identical points. The residuals in $\mathrm{XY}$ for two coordinates were about $12 \mathrm{~cm}$. The height was adapted by a systematic shift.

The defence tower Donjon was photogrammetrically recorded in 2010 with a Nikon D70 $(3008 \times 2000$ pixel $)$ and Nikkor lenses (focal length $18 \mathrm{~mm}$ and $28 \mathrm{~mm}$ ) in 77 images as wraparound image block at eye level for multi-image triangulation. Using the same photogrametric multi image triangulation approach the commandant's office was recorded in 2011 with the Nikon D90 $(4288 \times 2848$ pixel, focal length $20 \mathrm{~mm})$ in 92 images. The multiimage triangulation for image orientation and camera calibration was accomplished for the image block of the commandant's office with the software PICTRAN of technet $\mathrm{GmbH}$, for which on the average 15.7 points were measured per photo and each object point in seven photos. The bundle block adjustment gave a standard deviation of $1 \mathrm{~mm}$ for the control points and a measuring precision of $2.5 \mu \mathrm{m}$ in the photos. The image block of the defence tower was later used only for texture mapping of the 3D model.

The data recording of the fortress buildings and the structure inside and outside was realised with the terrestrial laser scanner Riegl VZ-400, in which the system was controlled with the software RiScanPro using a notebook (Figure 2 right). The defence tower Donjon was scanned from twelve scanner stations around the building in 2010. For the panorama scans of the fortress interior structure a scan resolution of $20 \mathrm{~mm}$ at $25 \mathrm{~m}$ distance was selected, while the building was scanned with a point spacing of $5 \mathrm{~mm}$ at the building wall. For the subsequent registration of the scans a total of 26 reflectors with a diameter of $6 \mathrm{~cm}$ (Figure 2 centre) were distributed in the scanned object area (14 in the field, four at the building and eight at the network stations). In 2011 the fortress walls and parts of the internal terrain were scanned from a total of 13 scan stations. 28 targets were set up around the object, and the coordinates were determined with the total station. The walls were scanned with a scan resolution of $20 \mathrm{~mm}$ at the wall. After each scan panorama images were additionally recorded with a calibrated digital camera the Nikon D700 (Figure 2 right), which were firmly

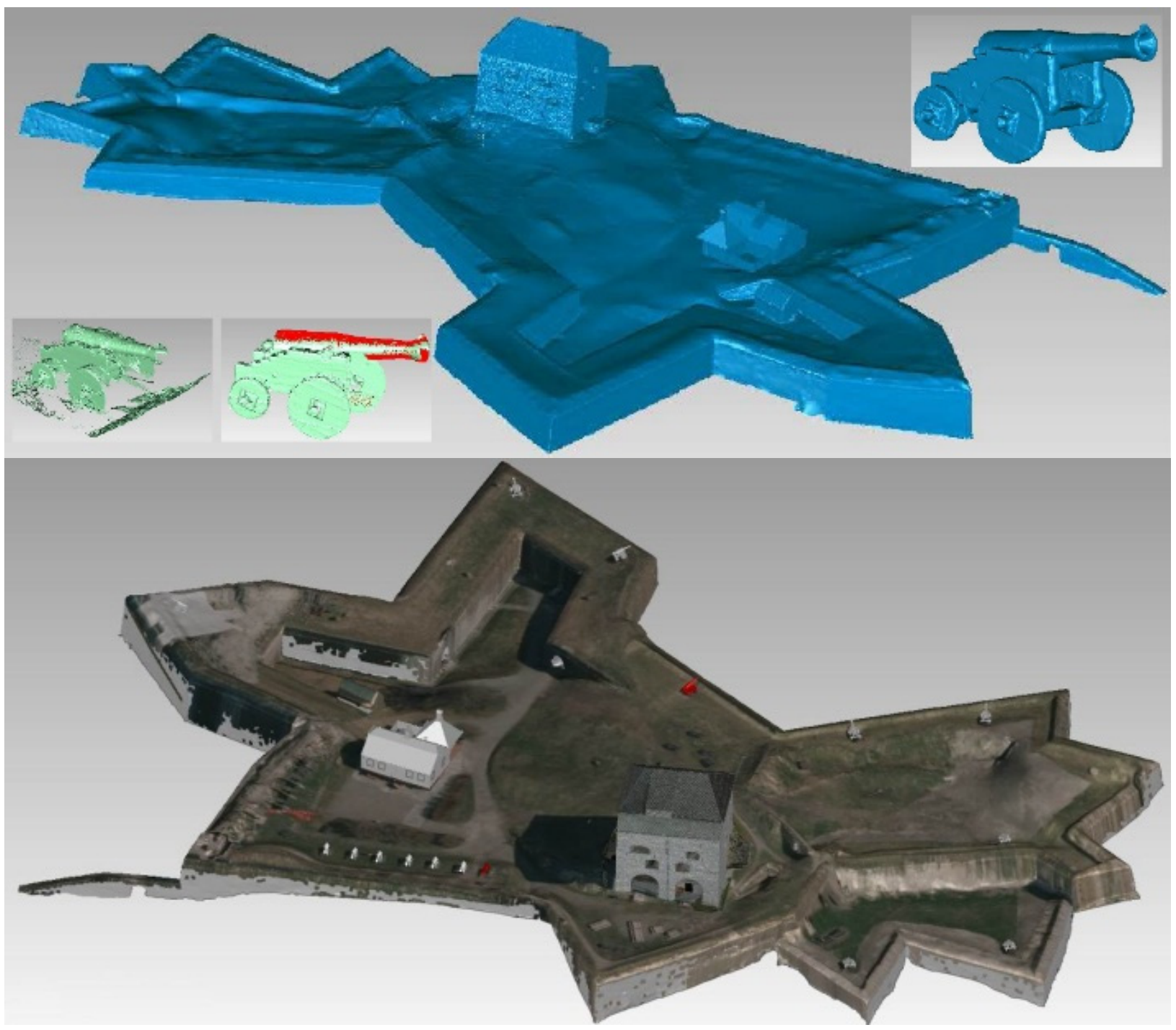

Figure 4: Fortification Kristiansten as meshed 3D model including modelled canons (top) and 3D model textured in Geomagic (bottom) 

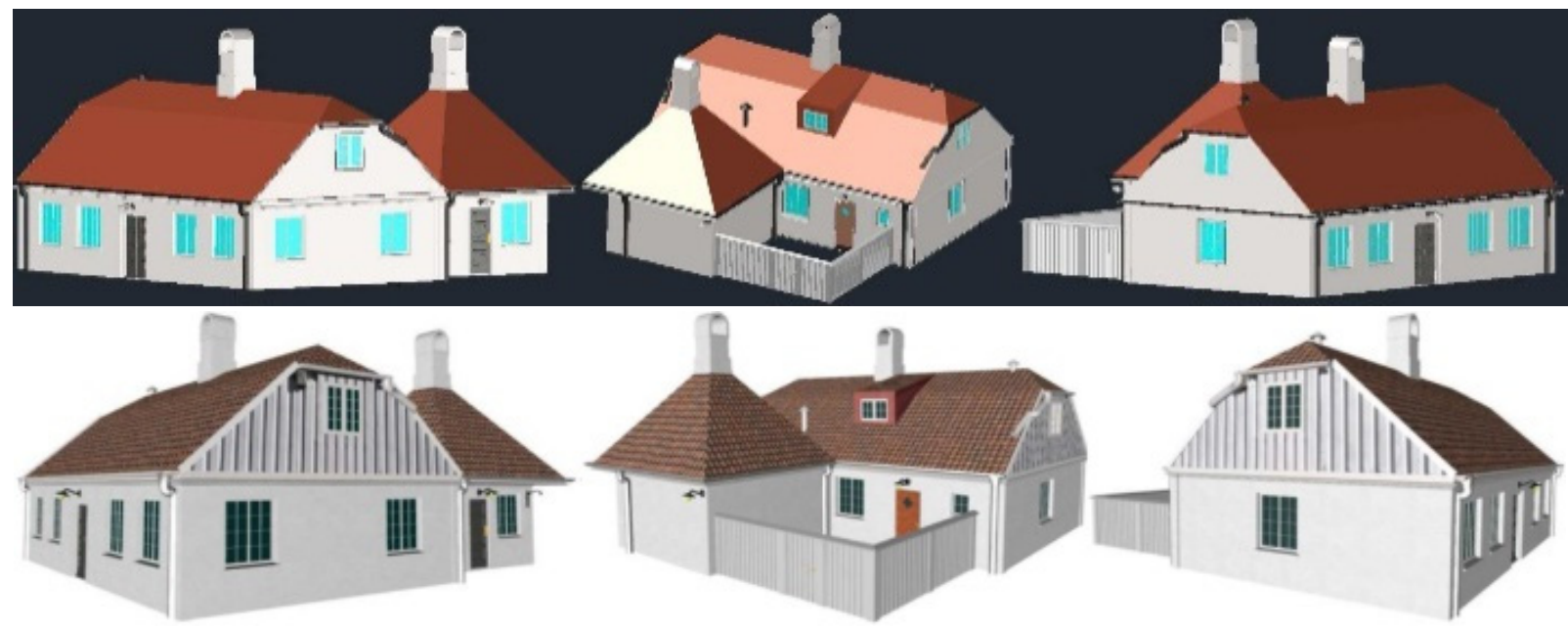

Figure 5: Commander's Residence of fortification Kristiansten - Constructed 3D CAD model from photogrammetric images (top) and 3D model textured in Cinema 4D (bottom)

installed on top of the scanner and which used a full format sensor with $36 \mathrm{~mm} \times 24 \mathrm{~mm}$ and a fixed Nikkor lens with $20 \mathrm{~mm}$ focal length. The image data served for the RGB colouring of the scans. After registration, geo-referencing and colouring of the scans in RiScanPro, the following results for the 13 scans from 2011 were achieved. The scans could be registered with a standard deviation of $5 \mathrm{~mm}$ for the control points, while a georeferencing was obtained with a standard deviation of $8.9 \mathrm{~mm}$. The results of the 12 scans from 2010 were slightly better. Due to filtering of the scans in RiScanPro not only rough erroneous measurements but also the vegetation could be eliminated, so that as basis for 3D modelling in Geomagic the data of the terrain, the walls and the buildings were available.

As the first step the defence tower Donjon was modelled after further filtering (smoothing/data reduction) of the point cloud by triangle meshing (edge length $3 \mathrm{~cm}$ ) in Geomagic. However, some holes still needed to be closed after meshing, in particular on the roof sectors. A closed meshing with 2.9 million triangles was generated and textured in Geomagic with the photos from the photogrammetric image block (Figure 3). Subsequently, the internal terrain model and the walls of the fortification were modelled by meshing with 1.6 million triangles (edge length $15 \mathrm{~cm}$ ). Furthermore, two different cannon types were modelled as characteristic objects of the fortress (see Figure 4 bottom in red). However, some cannon parts had to be constructed due to incomplete laser scanning (Figure 4 top in the corner). The cannon in Figure 4 consists of 133.000 triangles. After the construction of the two cannon types, each type was copied seven times and placed on the appropriate positions in the model of the fortification (Figure 4 bottom).

As the only object of the fortress the commandant's office was not only photogrammetrically recorded, but also photogrammetrically processed. After image orientation and camera calibration the points necessary for a detailed construction of the building in AutoCAD were measured in different photos using PICTRAN. The CAD construction was carried out exactly the same way as in many other projects of the HCU Hamburg (Kersten et al. 2003, Kersten et al. 2004, Kersten 2005, Kersten et al. 2006), i.e. after determination of the 3D points these were imported into AutoCAD, there connected to 2D polylines, from which volume bodies were created. In CAD Boolean operations can be applied to two or more surfaces or volumes, whereby new object parts can be achieved using intersection, subtraction or union of the surfaces or volumes.
Figure 5 shows the commandant's office of the fortress Kristiansten constructed in detail in AutoCAD. The entire modelling of the fortification and the processing of the whole data from the two field campaigns in 2010 and 2011 were brought to completion as a semester thesis in the context of the ERASMUS student exchange programme in the winter semester 2011/2012 at NTNU Trondheim (Maziull 2011).

\section{VISUALISATION}

\subsection{Video Sequence}

In the following winter semester 2012/2013 the same student worked on the 3D model of the entire fortress Kristiansten generated at NTNU Trondheim in co-operation with a fellow student in the context of the module Project Visualisation in the Master study programme Geomatics. In order to generate a video sequence, the entire model was further edited and textured in detail using the software Cinema 4D from the company MAXON Computer $\mathrm{GmbH}$. First the defence tower Donjon was revised in Geomagic by smoothing the meshing using filtering and by reducing the number of triangles to 2.4 million. The textures from Geomagic were not transferred when importing the data to Cinema 4D. Using the function texture mapping in Cinema 4D it turned out that the editing of complex, meshed models, such as the elevation model of the fortress, the walls and the defence tower Donjon, is clearly more labour intensive than the processing of 3D volume bodies (commandant's office). Since the meshed models consist of triangles and/or polygons, they must be attributed to defined surface areas in a Sisyphean task, before different textures can be manually assigned to them. However, automatic texture mapping of meshed models would also have been possible, if oriented image data of a calibrated camera was available in the same coordinate system as the 3D model (Kersten \& Stallmann 2012). For the preparation of suitable and qualitatively better textures, photos were cropped and rectified in the free software GIMP. For optimal illumination of the model in Cinema 4D different sources of light were provided and placed, since special characteristics of the different objects thereby can be emphasized well just for the evening or night. In total six spotlights were positioned around the defence tower to light up the foundation walls (Figure 6 top left). 


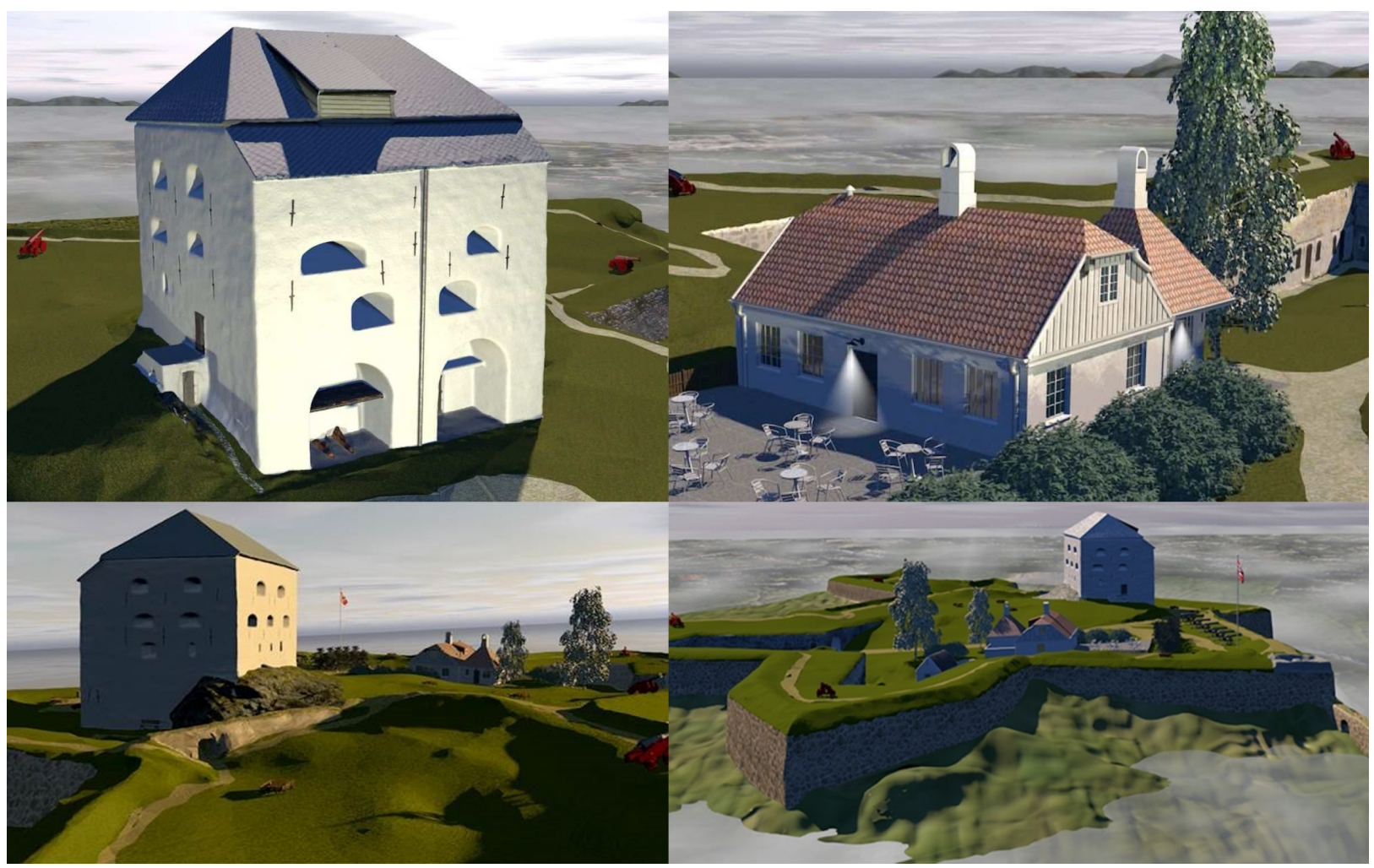

Figure 6: Cut-outs from the video of the fortress Kristiansten compiled in Cinema 4D - defence tower Donjon (top left) and commandant's office (top right) with lighting as well as perspective views on the entire fortress (bottom)

To generate a video sequence for this project, an object-oriented camera linked on a spline was selected, since it could be aligned to different objects on one hand and ran along the splines as camera path on the other hand. During the production of the image sequence single images were stored in the TIFF format after the rendering process with the standard renderer of Cinema $4 \mathrm{D}$, in order to lose no data in case of a process abort, e.g. by a system crash of the computer. The rendering of 6000 Frames ( 240 seconds or 4 minutes of video length with a rate of 25 frames per second) on a standard computer was very time-consuming with 784 hours (which corresponds to 33 days). Two film sequences (walk-through and fly-through) were generated in the photo manager of Cinema 4D and stored in the video format AVI. For the unification of the two sequences the video cut software iMovie of the company Apple was used. After audio effects were added to the film, e.g. bird twittering and mood music, the video was exported as HD 720p, which corresponds to a resolution of $1280 \times 720$ pixel in the format MOV. This video shows a data volume of $261 \mathrm{MB}$, while the 3D model is $371 \mathrm{MB}$ in the standard format of Cinema 4D (.c4d) and it uses 137 textures with a data volume of 192 Mbyte. The created video is available in the Internet in YouTube (https://www.youtube.com/watch?v=CtUh1El_exg). The expenditure of time for the video production was 175 hours without the time for rendering.

\subsection{Interactive 3D Visualisation}

Interactive visualisation is a representational form, where the viewing user selects the viewpoint, from which he would like to view the scene, and a game engine computes the selected perspective in real time and displays it. For this project the game engine Unity is used. It offers good performance and programmability using the language $\mathrm{C \#}$. A clear advantage in comparison to other common Engines is that it offers direct viewing capabilities on different platforms, such as PC (Windows, Mac), mobile devices (Android and iOS) and in the Web with a single click. This option is already available in the free version of Unity, which offers its use also within applications, for which no large investments are possible. Since a complete 3D model of the entire fortification is available, due to data recording by laser scanning, the movement of the viewer in the model is translated as a walk-through. Thereby the user moves by foot over the terrain like a human being visiting the real imposing structure. As an interface between computer and user a control system is installed using computer mouse and keyboard as well as the controller of the Playstation3 (Dualshock3). Using buttons and pointers (joystick) both the changes of the position and the viewing direction can be communicated to the system. More details about different controllers in Unity are described in Tschirschwitz et al. (2014). The output to the user can be carried out alternatively as simple perspective representation or in different forms of stereoscopic 3D. Adapted to different display devices the viewing can be effected using NVIDIA 3D vision for 3D monitors, or top-bottom or side by side stereo, e.g. for stereoscopic projectors.

Interactive visualisation can be performed using the textured model, which was basis of the video sequence rendered. Since no data reduction was carried out by producing a CAD model for the entire fortress, the representation (visualisation/display) can in this project only be offered on efficient hardware. Consequently, a presentation with smartphones, such as described in Tschirschwitz et al. (2014), must be relinquished here. The much to high point density of the triangle meshing exceeds the limitations of the processors and graphic chips used in modern smartphones. A strong data compression is not reasonable for this 
model, since high resolution is necessary for a realistic and attractive representation of this complex and challenging area.

\section{CONCLUSION AND OUTLOOK}

In this contribution it was shown that even larger projects in architectural photogrammetry could be successfully processed by the integration of practical projects into lectures. This is true for the integration into the Bachelor and Master Study programmes at HCU Hamburg as well as in lectures of international summer schools in the framework of ERASMUS lecturer and student exchange programs. The data acquisition and first working processes were realised in two summer schools for the example project fortress Kristiansten, in which students from different universities could intensively deal with the topic in lectures and practical project work within two weeks' time. The advanced and more in-depth processing of the project was then accomplished by a student in the context of an ERASMUS student exchange programme at NTNU Trondheim (Maziull 2011). In the following winter semester 2012/2013 the same student could continue working on the generated 3D model of the fortification Kristiansten in the course project visualisation of the Master study programme Geomatics. The entire model was arranged, further processed and textured very detailed in Cinema 4D, so that a video sequence could be generated, which is available at YouTube on the Internet. After the conversion of the 3D models from Cinema 4D into the game engine Unity further possibilities of immersive viewing for an interested user are given with interactive $3 \mathrm{D}$ visualisation on different output devices such as 3D monitors.

The integration of such practical projects in lectures of Bachelor and Master Study programmes promotes an increased motivation and willingness to learn, because the theoretical background and the practical projects can be linked well with each other. The preparation and execution of international summer schools demand an appropriate logistic and organisational expenditure, in addition to the necessary bureaucratic expenditure for ERASMUS programme. However, the benefit faces the expenditure by temporally limited, but intensive training, by the development of the personal network, the treatment of interesting projects and the extension of the own horizon by teaching and learning in an international environment.

\section{REFERENCES}

Bratberg, T.T.V., 2008. Trondheim Byleksikon. 2nd Edition, Kunnskapsforlaget, Oslo, ISBN 978-82-573-1762-1.

DAAD, 2012. ERASMUS (Special edition) - Happy birthday, ERASMUS! Die Erfolgsgeschichte der Europäischen Union feiert ihr 25-jähriges Bestehen. DAAD euroletter, Deutscher Akademischer Austauschdienst, August, 36 p. (Access at 19th January 2015), https://eu.daad.de/medien/eu/publikationen/sonderausgabe_euroletter.pdf.

Kavli, G., 1987. Norges festninger. Universitetsforlaget, ISBN 978-82-00-18430-0.

Kersten, T., Acevedo Pardo, C., 2003. Wie kommt das Ahrensburger Schloss in den Computer? - 3D-Gebäudeerfassung und Visualisierung durch digitale Photogrammetrie. DenkMal! Schleswig Holstein, Zeitschrift für Denkmalpflege in Schleswig Holstein, Landesamt für Denkmalpflege in Schleswig-Holstein (Hrsg.), Jahrgang 10, 2003, Westholsteinische Verlagsanstalt Boyens \& Co., Heide, pp. 48-54.
Kersten, T., Eilmus, B., Lindstaedt, M., Acevedo Pardo, C., 2003. 3D-Erfassung und Visualisierung des Celler Schlosses durch digitale Architekturphotogrammetrie. Photogrammetrie, Laserscanning, Optische 3D-Messtechnik - Beiträge der Oldenburger 3D-Tage 2003, Th. Luhmann (Hrsg.), Wichmann Verlag, Heidelberg, pp. 213-222.

Kersten, T., Acevedo Pardo, C., Lindstaedt, M., 2004. 3D Acquisition, Modelling and Visualization of north German Castles by Digital Architectural Photogrammetry. International Archives of Photogrammetry, Remote Sensing and Spatial Information Sciences, Istanbul, Turkey, Vol. XXXV, Part B2, pp. 126-132.

Kersten, T., 2005. Digitale Architekturphotogrammetrie als ein Beispiel für die praxisorientierte Ausbildung an der HAW Hamburg. HAW Hamburg, Fachbereich Geomatik, Festschrift zur Verabschiedung von Prof. Dr. h.c. Jürgen Zastrau, 8. Juli 2005.

Kersten, T., Biebermann, M., Schneider, M., 2006. 3D-Erfassung und Modellierung des Duderstädter Westerturmensembles durch Kombination von digitaler Architekturphotogrammetrie und terrestrischem Laserscanning. Photogrammetrie, Laserscanning, Optische 3D-Messtechnik - Beiträge der Oldenburger 3D-Tage 2006, Th. Luhmann/C. Müller (Hrsg.), Wichmann Verlag, Heidelberg, pp. 254-263.

Kersten, T., 2006. Combination and Comparison of Digital Photogrammetry and Terrestrial Laser Scanning for the Generation of Virtual Models in Cultural Heritage Applications. The 7th International Symposium on Virtual Reality, Archaeology and Cultural Heritage, VAST (2006), M. Ioannides, D. Arnold, F. Niccolucci, K. Mania (Editors), Hilton Nicosia, Cyprus, Oct. 30 - Nov. 4, 2006, pp. 207-214.

Kersten, T., 2007. Virtual Reality Model of the Northern Sluice of the Ancient Dam in Marib/Yemen by Combination of Digital Photogrammetry and Terrestrial Laser Scanning for Archaeological Applications. International Journal of Architectural Computing, Special Focus on Cultural Heritage, 02 (05), Multi-Science, pp. 339-354.

Kersten, T., Büyüksalih, G., Baz, I., Jacobsen, K., 2009. Documentation of Istanbul Historic Peninsula by Kinematic Terrestrial Laser Scanning. The Photogrammetric Record, 24(126): pp. 122-138 (June 2009).

Kersten, T., Lindstaedt, M., 2012. Virtual Architectural 3D Model of the Imperial Cathedral (Kaiserdom) of Königslutter, Germany through Terrestrial Laser Scanning. In: EuroMed 2012 - Int. Conference on Cultural Heritage, Ioannides, M.; Fritsch, D.; Leissner, J.; Davies, R.; Remondino, F.; Caffo, R. (Eds.), Lecture Notes in Computer Science (LNCS), Volume 7616, Springer-Verlag Berlin Heidelberg, pp. 201-210

Kersten, T., Stallmann, D., 2012. Automatic Texture Mapping for Architectural and Archaeological 3D Models. In: International Archives of Photogrammetry, Remote Sensing and Spatial Information Sciences, Melbourne, Australia, Vol. XXXIX, Part B5, pp. 273-278.

Kersten, T., Mechelke, K., 2013. Fort Al Zubarah in Katar - 3DModell aus Scanner- und Bilddaten im Vergleich. AVN Allgemeine Vermessungs-Nachrichten, 2/2013, pp. 50-58. 
Lindstaedt, M., Kersten, T., Mechelke, K., Götting, M., Heiden, R., 2008. Virtuelles 3D-Modell der antiken Tempelanlage in Sirwah/Jemen zur archäologischen Objektdokumentation durch terrestrisches Laserscanning und Photogrammetrie. Publikationen der Deutschen Gesellschaft für Photogrammetrie, Fernerkundung und Geoinformation e.V., Band 17, Hrsg. E. Seyfert, 28. Wissenschaftlich-Technische Jahrestagung der DGPF, 23.-25. April 2008 in Oldenburg, pp. 59-68.

Lindstaedt, M., Mechelke, K., Schnelle, M., Kersten, T., 2011. Virtual Reconstruction of the Almaqah Temple of Yeha in Ethiopia by Terrestrial Laser Scanning. Proceedings of the 4th ISPRS International Workshop 3D-ARCH 2011: "3D Virtual Reconstruction and Visualization of Complex Architectures", Fabio Remondino, Sabry El-Hakim (Eds.), International Archives of Photogrammetry, Remote Sensing and Spatial Information Sciences, Trento, Italy, Volume XXXVIII-5/W16.

Maziull, L., 2011. 3D Modelling and Visualization of Kristiansten Fortress in Trondheim. Semester Thesis at NTNU Trondheim, December.

Maziull, L., 2013. Visualisierung der Festung Kristiansten in Trondheim, Norwegen in Cinema 4D. Semester Thesis at HCU Hamburg, March.

Tschirschwitz, F., Kersten, T., Zobel, K., 2014. Interactive 3D Visualisation of Architectural Models and Point Clouds Using Low-Cost-Systems. In: Progress in Cultural Heritage. Documentation, Preservation, and Protection. 5th International Conference, EuroMed 2014, Limassol, Cyprus, November 3-8, 2014, Ioannides, M., Magnenat-Thalmann, N., Fink, E., Zarnic, R., Yen, A.-Y., Quak, E. (Eds.), Lecture Notes in Computer Science (LNCS), Volume 8740, Springer International Publishing Switzerland 2014, pp. 268-278. 